\title{
Attitudes and perceptions towards performance- enhancing substance use in Johannesburg boys high school sport
}

\author{
Philippe Gradidge (BSpSc (Hons) Biokinetics) \\ Yoga Coopoo (DPhil, FACSM) \\ Demitri Constantinou (MB BCh, BSc Med Hons, FFIMS) \\ Centre for Exercise Science and Sports Medicine, Faculty of Health Sciences, University of the Witwatersrand, Johannesburg
}

\begin{abstract}
Introduction. The environment of youth sport in South Africa has transformed considerably, where adolescent athletes are faced with more pressure from coaches, peers and parents to perform well. Some of the athletes are using nutritional supplements or prohibited means such as doping to cope with these pressures and gain an edge in competition.

Objectives. In view of the lack of literature investigating the use of doping in South African adolescents, the objective of the study was to determine the attitudes and perceptions of male adolescent athletes regarding performance-enhancing substance (PES) use.

Methods. The design of the study was cross-sectional and used a self-administered questionnaire. A sample of participants was obtained from male adolescent high school athletes involved in 1st and 2nd high school sports teams in Johannesburg boys high schools. Participants were invited to volunteer to participate in the study. Questionnaires were completed under conditions that were similar to an examination situation. Demographic data were analysed using descriptive statistics.

Results. The majority (91\%) of the athletes indicated a belief that the number of athletes using PES in sport is increasing. Eightyfour per cent of them felt that there was pressure placed on them to use PES to win. Only $55 \%$ of respondents believed that doping tests would prohibit the use of banned substances and $91 \%$ did not believe that the sale of prohibited substances should be banned. The majority $(88 \%)$ believed there is a need for further education.
\end{abstract}

\section{CORRESPONDENCE:}

\section{Philippe Gradidge}

Centre for Exercise Science and Sports Medicine

University of the Witwatersrand

PO Box 85484

2029 Emmarentia

Tel: +27 117173372

Fax: +27 866092017

E-mail: philippe.gradidge@wits.ac.za
Conclusion. Although there is enormous pressure on high school boys to use PES, their knowledge is lacking, especially with regard to doping in sport.

\section{Introduction}

The World Anti-Doping Agency (WADA) is the leader in the fight against doping in sport. This agency publishes a list of prohibited substances, which is updated on an annual basis. ${ }^{1}$ The South African Institute for Drug-Free Sport (SAIDS) is one of the many signatories that complies with WADA's prohibited list, and also publishes an annual prohibited list based on South African brand names. ${ }^{2}$ Doping is regarded as a form of cheating where athletes use substances that are on these prohibited lists, predominantly for gaining an edge over their competitors. ${ }^{3}$ An alternative to doping can be nutritional substance use, which helps to improve the health and performance of active adolescent athletes. Despite strong efforts in attempting to eliminate doping in sport, the use of drugs and prohibited substances to boost performance is common among athletes. ${ }^{3}$ South African adolescent sport seems to have changed dramatically, as it appears that there are greater pressures placed on adolescent athletes to excel in sport and some are using performance-enhancing substances (PES) to cope with the demands placed on them. ${ }^{4-6}$ The problem is that some of the PES are listed as prohibited, and adolescent athletes might be tempted to use these because the pressures and stresses facing them may be too immense to resist. ${ }^{1}$

Just as the competitive nature of professional sports has led to athletes doing whatever they can to give themselves an edge in competition, and sometimes placing their well-being at risk, it seems to have also trickled down into youth sports. Furthermore, many of the adolescent athletes who do not believe they are successful at a competitive level may choose to take prohibited PES. ${ }^{7}$ Additionally, in spite of the view that the use of doping remains 'fundamentally contrary to the spirit of sport', ${ }^{8}$ athletes are using prohibited PES in sport. Some athletes are advocating that these substances be legitimately used for the enhancement of performance best in competition. ${ }^{9,10}$ These banned products may enable them to improve their athletic performance, help with recovery from hard physical training and improve self-image in the short term; however, in the long run there may be negative costs to their well-being and general health. ${ }^{7}$ Therefore, the purpose of this study was to investigate the attitudes and perceptions of male adolescent competitive athletes from Johannesburg boys high schools towards PES use in sport. 


\section{Methods}

The study used a cross-sectional method design with a self-administered questionnaire, which had been adapted from a study that investigated doping in elite South African athletes. ${ }^{11}$ The reliability and validity of the adapted questionnaire was tested in a pilot study, and was found to be $83 \%$ reliable. Further validation of the questionnaire was provided by professionals practising in the fields of biokinetics, exercise science and sports medicine. The questionnaire was formulated to elicit responses on PES and nutritional supplements used in order to improve performance. The participants' attitudes and perceptions regarding PES use were solicited, such as beliefs about PES use in sport and whether education on doping was needed. A sample of participants was attained from male adolescent high school athletes, aged between 15 and 18 years, involved in 1st and 2nd team high school sports from public and private Johannesburg boys high schools. The Provincial Department of Education granted permission to conduct the study and ethical clearance (M060953) was obtained from the University of the Witwatersrand Human Research Ethics Committee.

Arrangements were made to conduct the study on a date and time that was convenient for the high schools that gave consent to participate. Those participants who volunteered to participate provided minor assent and parental informed consent. They completed the questionnaire under conditions where participants were not allowed to communicate with each other. The participants were also given the opportunity to ask questions pertaining to the content and completion of the questionnaire. Questionnaires were handed in to the researcher immediately after completion. The collected data were then group-analysed using the Epi Info (TM) 3.5.1 statistical software package. Data were descriptive and involved summary statistics displaying frequencies and percentages.

\section{Results}

The responses of the participants were coded and missing values were not included in the analysis because it was not possible to determine what the participants would have answered in these cases.

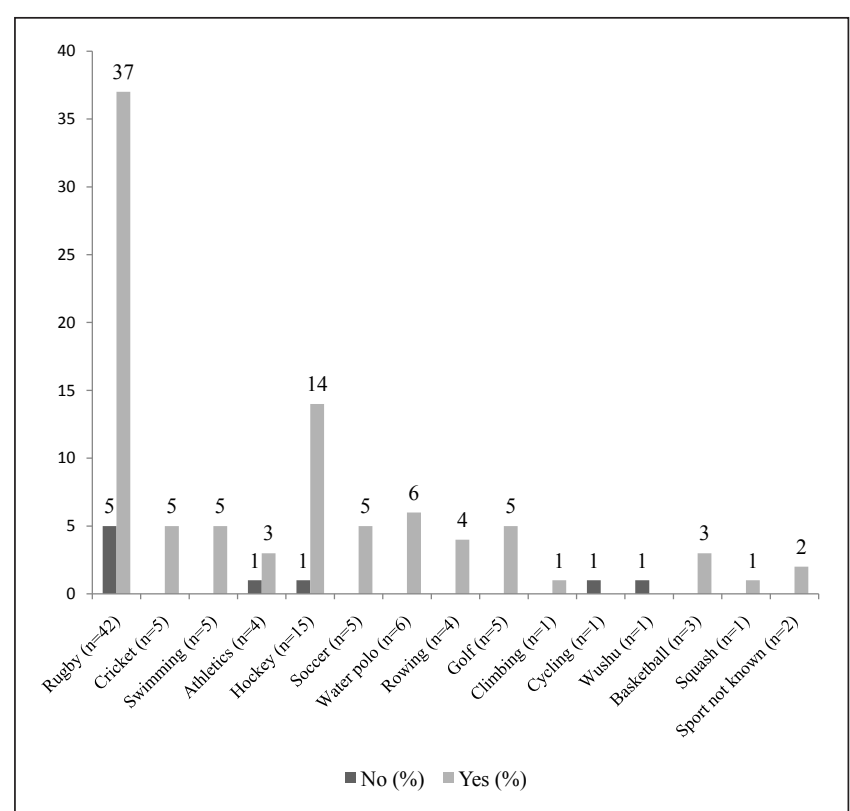

Fig. 1. Main high school sport participation and establishing whether PES use is believed to be on the increase $(\mathrm{N}=100)$
Some of the participants did not answer all questions and in most cases multiple responses were given to certain questions where more than one option could have been chosen. These multiple responses were taken into account when analysing the data.

\begin{tabular}{|c|c|}
\hline \multicolumn{2}{|c|}{$\begin{array}{l}\text { TABLE I. Prevalence of substances used and reasons } \\
\text { for using PES }(N=100)\end{array}$} \\
\hline Prevalence of PES use & $\%$ \\
\hline Yes & 30 \\
\hline No & 64 \\
\hline Non-response & 6 \\
\hline \multicolumn{2}{|l|}{ Common prohibited substances used } \\
\hline Anabolic androgenic steroids $(N=100)$ & 4 \\
\hline Growth hormone $(N=100)$ & 5 \\
\hline Adrenaline /ephedrine $(N=100)$ & 4 \\
\hline Insulin $(N=100)$ & 2 \\
\hline \multicolumn{2}{|l|}{ Common non-prohibited supplements used } \\
\hline Caffeine supplementation $(N=28)$ & 57 \\
\hline Creatine supplementation $(N=84)$ & 32 \\
\hline Carbohydrates supplementation $(N=90)$ & 54 \\
\hline Protein supplementation $(N=88)$ & 61 \\
\hline Vitamin supplementation $(N=88)$ & 61 \\
\hline \multicolumn{2}{|l|}{ Reasons for using PES } \\
\hline Assists me in coping with the stresses of sport $(N=24)$ & 29 \\
\hline Helps to improve the way I perform in sport $(N=25)$ & 68 \\
\hline \multicolumn{2}{|l|}{ Helps to reduce food craving in order to } \\
\hline decrease my body weight $(N=25)$ & 32 \\
\hline I feel afraid of being dropped from the team $(N=24)$ & 21 \\
\hline I will have a better chance of making the team $(N=25)$ & 28 \\
\hline
\end{tabular}

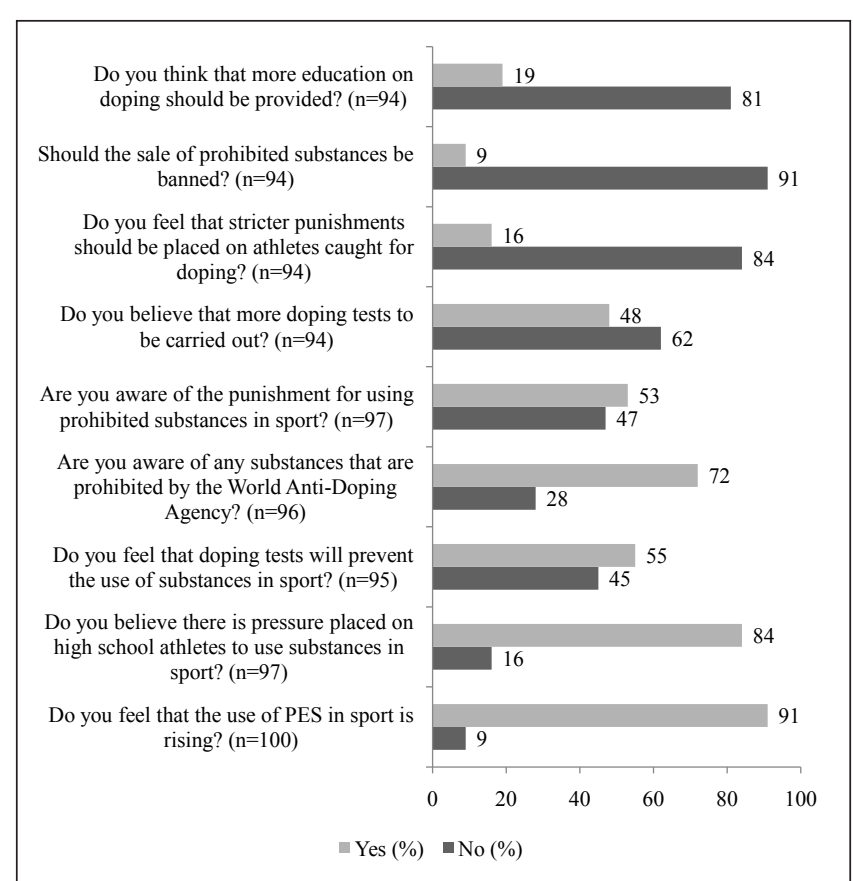

Fig. 2. General attitudes and perceptions towards PES use in sport $(\mathrm{N}=100)$. 


\section{Demographic data}

Of the 100 ( $81 \%$ response rate) competitive male adolescent athletes investigated, most were $17-18$ years old $(78 \%)$, while a minority were $15-16$ years old (22\%). They were from grades $10(11 \%)$, $11(67 \%)$ and $12(22 \%)$. The majority of these participants (42\%) played rugby (Fig. 1).

\section{Prevalence of substance use}

A number of the participants (30\%) indicated using PES for enhancement of performance (Table I). Table I displays the prevalence of substances utilised for performance enhancement and the rationale participants had for using them. The majority of these athletes $(68 \%)$ indicated that they used PES to have a better performance output in sport.

\section{General attitudes and perceptions towards PES use}

The responses on the participants' general attitudes and perceptions towards doping are shown in Fig. 2.

Most of the participants (91\%) felt that PES usage in sport was on the increase. Only $55 \%$ of them believed that testing for substance abuse would serve as a deterrent. Over half of the participants (53\%) were aware of the punishment that would be meted out for substance abuse, and $72 \%$ of them acknowledged that they knew of substances that were prohibited by WADA.

\section{More specific attitudes towards PES use}

The adolescent athletes were asked to respond to twelve statements regarding their attitudes and perceptions towards the use of PES

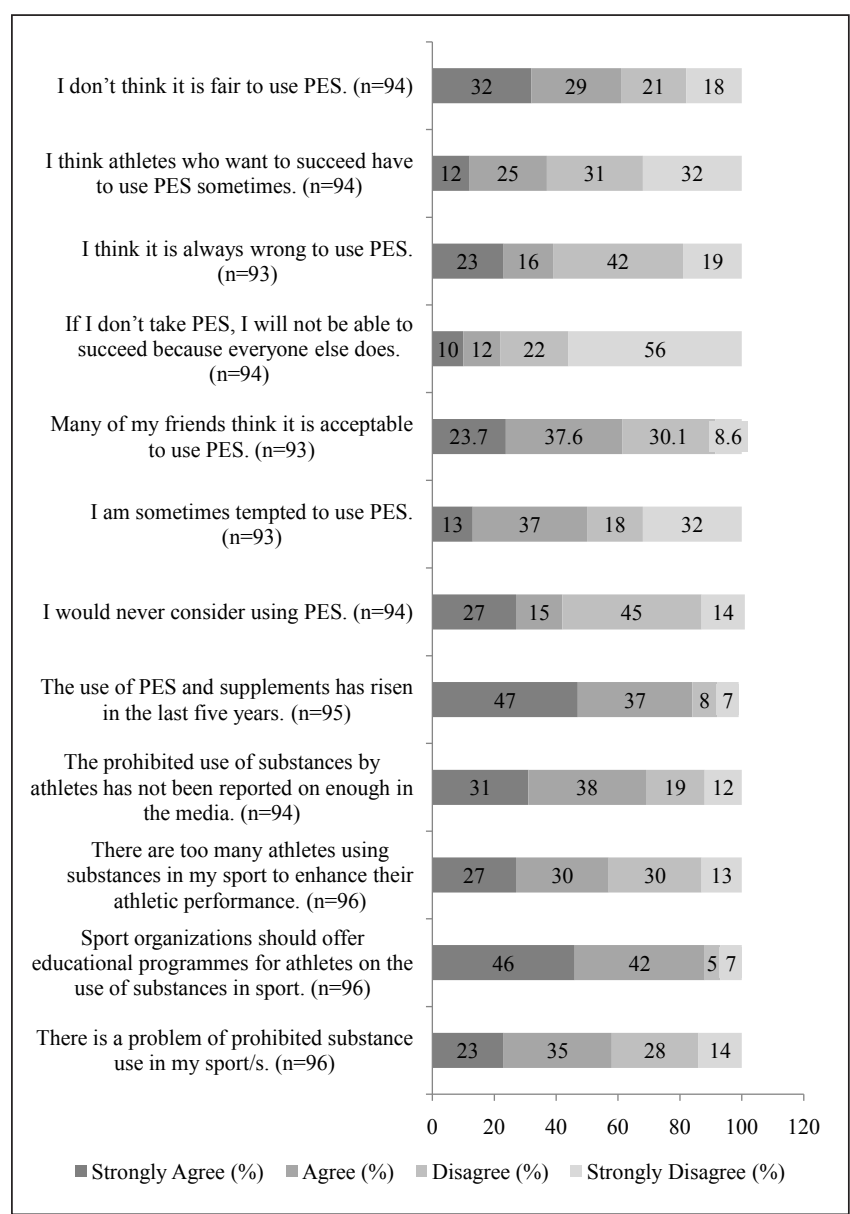

Fig. 3. Specific attitudes and perceptions of high school learners towards doping in sport $(\mathrm{N}=100)$. in sport. Fig. 3 illustrates specific attitudes and perceptions towards doping in sport. Participants' answers to this section were analysed and calculated according to the total amount of responses per statement.

Thirty-five per cent of the participants agreed that prohibited substances were being used in their sports, and 30\% agreed that there were several athletes making use of substances to increase their performance. Sixty one per cent of the participants agreed that PES use in sport is unethical.

\section{Sources of information for performance-enhancing sub- stance use}

Fig. 4 displays where the athletes obtained their information on PES usage. Multiple responses were given in this section, thus the data were calculated by taking into account the number of individual responses per question.

The highest ranking source of information on PES usage was the Internet $(74 \%)$, followed by magazines $(72 \%)$, from a friend $(66 \%)$, the coaching staff $(66 \%)$, and parents $(40 \%)$. Some of the other mentioned sources of information on PES use in sport were from personal trainers $(33 \%)$, information brochures $(31 \%)$, newspapers $(31 \%)$, the pharmacist $(24 \%)$, and $23 \%$ indicated that they attained information from the television and their school.

\section{Discussion}

The Olympic Charter's goal of 'friendship, solidarity and fair play'12 in sport still needs to become a reality, and should become a core pillar in the fight against doping in sport. Using prohibited substances in sport is unethical and unfortunately the adolescent athletes using them may be doing so at the cost of their well-being and physiological development. Even though most participants agreed that doping was cheating, they also reported immense pressure to perform and would perhaps turn to PES as a coping mechanism or performance advantage. It is for this reason that the anti-doping struggle in adolescent sport should not be taken without due consideration.

Adolescent athletes who have the potential to be successful in sport appear to be required to give maximum effort throughout the whole high school sporting season and this may be too stressful for them. Parents, coaching staff and friends may sometimes place unrealistic demands on individuals and this could indirectly tempt or even encourage the use of prohibited PES in sport in some adolescent athletes. $^{3,13}$ It may be beneficial for all those involved in high school sport, such as parents/guardians, coaching staff, teachers and the athletes, to be taught that losing or coming second or third is acceptable. In reality, even the elite and professional athletes have times when they do not win or days when performance is not at a peak level. Hence, this approach could enable adolescent athletes to learn that fair game play and honest interaction with opponents are more essential than winning all the time. ${ }^{14}$

The results indicate that $4 \%$ of the participants are using anabolic androgenic steroids. These athletes may have used this banned substance in spite of the well-known harmful side-effects. ${ }^{15-17}$ If this pattern continues, adolescent sport can evolve into a win-at-all-costs phenomenon, where doing whatever it takes to excel in competition may become routine practice in some athletes. With the evolution of new PES products being engineered and sold on the black market, the adolescent athletes using them on a regular basis could be bearing the burden of utilising unknown substances which may have harmful and irreversible side-effects. Some of these potential negative effects could include addictive and antisocial behaviour, as well as increased risk of heart disease. ${ }^{3,13}$ These side-effects may 


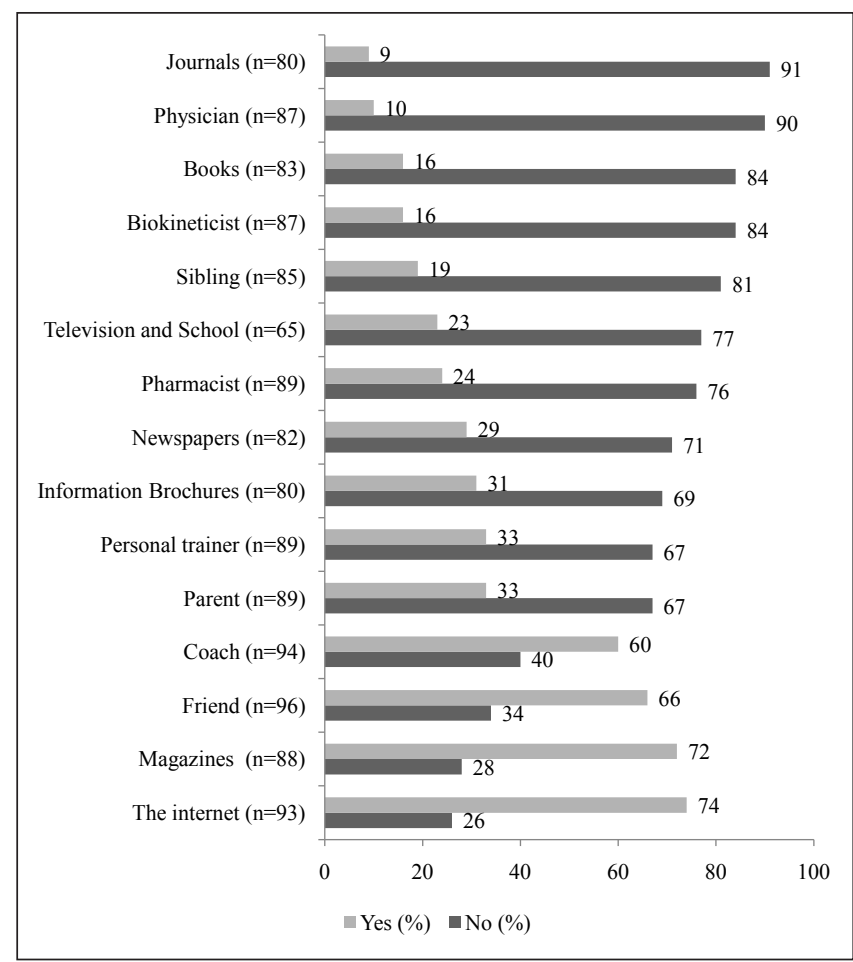

Fig. 4. Sources of information for PES use $(\mathrm{N}=100)$.

result in poor health and poor performance in the long term. Although most of the athletes reported using PES for helping achieve optimal performance, most disagreed that taking PES was necessary to succeed (Fig. 3).

It is certainly acceptable that banned substances may induce a performance that is unattainable with 'normal' physiology or ethical means. Nevertheless, it is also true that peak performance can be enhanced via ethical means without incurring the health risks and moral compromises of drug use. For instance, adolescent athletes can be taught how to improve performance through legitimate means, such as periodisation in training and sound nutrition. ${ }^{18}$ Periodisation is a means of planning a training programme to ensure adequate recovery for the body, thus allowing the athlete to peak at the right times. ${ }^{18}$ Nutritional supplement use is another way of helping active adolescents attain a healthy lifestyle and optimal performance in sport. These favourable and safe methods can give adolescent athletes a more ethical means of achieving their best in sport. Moreover, the inclusion of psychology can act as a tool to improve adolescent athletes' self-image and mastery in sport. In addition, more focus should be placed on educating adolescent athletes as well as others involved with them on the use of doping in sport and its adverse effects. The results show that the Internet was the main source of information (74\%) on PES use in sport. This result is possibly because the high schools involved in the study have access to this resource and its use as a means of finding out information is generally encouraged by teachers. The Internet can sometimes be a good and reliable source of information, but the ability of the athletes to critically discern this is questionable. Perhaps the skills of critically analysing information resources could be taught as part of the normal high school curriculum, thus equipping the athletes with the ability to make mature and ethical decisions regarding PES use.

Education is perhaps one of the key vehicles that can aid in discouraging the use of doping and prohibited PES in adolescent sport. Even though a large number of participants in this study $(72 \%)$ knew of some substances that were on WADA's list of prohibited substances, the findings of this study show that $46 \%$ strongly agreed and $42 \%$ agreed that education would provide a means of improving the awareness of prohibited PES, their adverse effects, and the rules regarding PES use in sport. These results confirm that the majority $(88 \%)$ of the participants have a desire to know more about doping and feel that sporting bodies and other organisations should be providing this. Doping may essentially tear down what is decent, ethical and good regarding adolescent sport. It may even corrode societal confidence and endanger the athletic adolescent population. Educational drives should go beyond the elite, professional athlete and target those involved in recreational sports, where drug testing is not commonly seen. ${ }^{19}$ It is important to ensure that developing adolescent athletes are taught the fundamentals of fair play and good character while in the developmental stages of sports play. It would also be useful to include coaching staff, dieticians and other medical professionals who are involved with anti-doping strategies to aid and inform adolescent athletes on the use and abuse of drugs in sport, what factors lead to doping, and how to deal with these. ${ }^{20}$ It seems that a holistic approach to combating the problem of doping could provide a way of restoring the ethical values in sport.

\section{Conclusion}

The knowledge regarding the use of doping in adolescent sport seems to be deficient, and the majority of the participants (88\%) indicated that there was a need for more education on prohibited and non-prohibited PES use. There is great pressure placed on the athletes to succeed in high school sport, and some of these participants use PES to cope with the pressures. It appears that most adolescent athletes in this sample are not taking prohibited PES, as the non-prohibited substances were more commonly used. However, the need for educational intervention is still important to address the problem of doping in adolescent sport. It is recommended that these educational strategies be applicable and relevant to adolescent athletes, and perhaps be introduced at an early age to increase anti-doping attitude and develop a character of socially acceptable sporting behaviour.

\section{REFERENCES}

1. World Anti-Doping Agency. http://www.wada-ama.org/en>. Accessed 10 June 2010.

2. South African Institute for Drug-Free Sport. <http://drugfreesport.org.za/> Accessed 10 June 2010.

3. Clisby L. Drugs and the athlete. In: Brukner P, Khan K, eds. Clinical Sports Medicine, 2nd ed. Sydney: McGraw-Hill, 2005.

4. Lambert MI, Titlestad SD, Schwellnus MP. Prevalence of androgenicanabolic steroid use in adolescents in two regions of South Africa. S Afr Med J 1998;88(7):316-330.

5. Schwellnus MP, Lambert MI, Todd MP, Juritz JM. Androgenic anabolic steroid use in matric pupils. A survey of prevalence of use in the western Cape. S Afr Med J 1992;82:154-158.

6. Sports Information and Science Agency. Drug Related Issues in Sport and Awareness survey. Pretoria: National Department of Sport and Recreation, 1999.

7. Mayo Clinic Staff. Performance-enhancing drugs and your teen athlete. <http://www.mayoclinic.com:80/health/performance-enhancing-drugs/ SM00045>. Accessed 16 March 2009. Mayo Foundation for Medical Education and Research, 2009.

8. Todd T. A history of the use of anabolic steroids in sport. In: Berryman JW, Park RJ, eds. Sport and Exercise Science Essays in the History of Sports Medicine. Urbana-Chicago: University of Illinois Press, 1992.

9. Koyser S, Mauren A, Miah A. Viewpoint legalization of performance enhancing drugs. Lancet 2005;366:21.

10. Savulescu J, Faddy B, Clayton M. Why we should allow performance enhancing drugs in sport. Br J Sports Med 2004;38:666 -670.

11. Coopoo $Y$, Jakoet I. Substance abuse and knowledge thereof among elite South African athletes. S Afr J Sports Med 2000;7(3):10-13. 
12. International Olympic Committee. Olympic Charter. <http://multimedia. olympic.org/pdf/en_report_122.pdf>. Accessed 16 March 2009.

13. British Medical Association. Drugs in Sport: The Pressure to Perform. London: BMJ Books, 2002.

14. Gradidge $P$, Constantinou $D$, Coopoo $Y$. The use of performance enhancing substances by high school boys. <http://web.wits.ac.za/NewsRoom/ Newsltems/PerformanceEnhancingSubstances.htm $>$. Accessed 28 May 2010.

15. Haller CA, Benowitz NL. Adverse cardiovascular and central nervous system events associated with dietary supplements containing ephedra alkaloids. N Engl J Med 2000;343:1833-1838.
16. Gruber AJ, Pope HG. Ephedrine abuse among 36 female weight lifters. Am J Addict 1998;7:256-261.

17. Gill A. Faster, higher stronger: confessions of an ephedrine junkie. The Globe and Mail 2002 March 9:L3.

18. Lambert M. Performance enhancement by allowed means. 3rd International Football Medicine Conference, Sun City, South Africa, 2010.

19. Hoppeler HH, Kamber MF, Melia PS. Doping and prevention of doping. International co-operation. Clin J Sport Med 1995;5:79-81.

20. Verroken M, Mottram DR. Doping control in sport. In: Mottram DR, ed. Drugs and Sport, 2nd ed. London: E\&FN Spon, 1996.

\section{$4^{\text {th }}$ Clinical Sports Medicine Conference}

\section{'Injury Prevention and Protection of the Health of the Athlete'}

\section{Third Announcement and Programme Outline Wednesday 13 - Friday 15 October 2010 \\ Hosted by: \\ Clinical Sports and Exercise Medicine Research Group, UCT/MRC Research Unit for Exercise Science and Sports Medicine (ESSM), Department of Human Biology, Faculty of Health Sciences, University of Cape Town, South Africa}

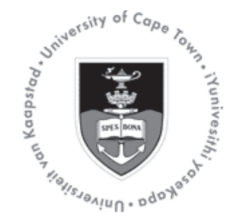

Congress Coordinator: Deborah McTeer of the University of Cape Town Conference Management Centre.

Register online at http://www.uct-cmc.co.za/Conferences/conf-main.asp?Conf ID=133\&Page=Home

For any enquiries please contact Fatima Saban - Fatima.Saban@uct.ac.za / Tel +27 214066330 